\title{
Intensive care unit admission in chronic obstructive pulmonary disease: patient information and the physician's decision-making process
}

\author{
Matthieu Schmidt ${ }^{1,2,3}$, Alexandre Demoule ${ }^{3,4,5}$, Emmanuelle Deslandes-Boutmy ${ }^{6}$, Marine Chaize ${ }^{7}$,
} Sandra de Miranda ${ }^{7}$, Nicolas Bèle ${ }^{7}$, Nicolas Roche ${ }^{8}$, Elie Azoulay ${ }^{7}$ and Thomas Similowski ${ }^{1,2,3^{*}}$

\begin{abstract}
Introduction: ICU admission is required in more than $25 \%$ of patients with chronic obstructive pulmonary disease (COPD) at some time during the course of the disease. However, only limited information is available on how physicians communicate with COPD patients about ICU admission.

Methods: COPD patients and relatives from 19 French ICUs were interviewed at ICU discharge about their knowledge of COPD. French pulmonologists self-reported their practices for informing and discussing intensive care treatment preferences with COPD patients. Finally, pulmonologists and ICU physicians reported barriers and facilitators for transfer of COPD patients to the ICU and to propose invasive mechanical ventilation.

Results: Self-report questionnaires were filled in by 126 COPD patients and 102 relatives, and 173 pulmonologists and 135 ICU physicians were interviewed. For $41 \%(n=39)$ of patients and $54 \%(n=51)$ of relatives, ICU admission had never been expected prior to admission. One half of patients were not routinely informed by their pulmonologist about possible ICU admission at some time during the course of COPD. Moreover, treatment options (that is, non-invasive ventilation, intubation and mechanical ventilation or tracheotomy) were not explained to COPD patients during regular pulmonologist visits. Pulmonologists and ICU physician have different perceptions of the decision-making process pertaining to ICU admission and intubation.

Conclusions: The information provided by pulmonologists to patients and families concerning the prognosis of COPD, the risks of ICU admission and specific care could be improved in order to deliver ICU care in accordance with the patient's personal values and preferences. Given the discrepancies in the decision-making process between pulmonologists and intensivists, a more collaborative approach should probably be discussed.
\end{abstract}

\section{Introduction}

Chronic obstructive pulmonary disease (COPD) is an increasingly common cause of death [1]. At severe stages of the disease, episodes of acute respiratory failure often require intensive care unit (ICU) admission [2]. Although the corresponding acute mortality is relatively low [3] and lower than that of other diseases [4], outcomes after an exacerbation are poor $[3,5,6]$. Disease severity, comorbidities, and impairment of activities of daily living are salient

\footnotetext{
* Correspondence: thomas.similowski@psl.aphp.fr

'Sorbonne Universités, UPMC Univ Paris 06, UMR_S 1158 'Neurophysiologie Respiratoire Expérimentale et Clinique', 47-83 boulevard de l'Hôpital, 75013 Paris, France

${ }^{2}$ INSERM, UMR_S 1158 'Neurophysiologie Respiratoire Expérimentale et Clinique', 47-83 boulevard de l'Hôpital, 75013 Paris, France

Full list of author information is available at the end of the article
}

prognostic factors $[3,5,6]$. Of note, intubation and invasive ventilation during an episode of exacerbation are associated with longer durations of stay and increased in-hospital and post-hospital mortality rates [7]. In this context, the American Thoracic Society/European Respiratory Society task force on COPD diagnosis and management [8] has recommended that 'Healthcare providers should assist patients during stable periods of health to think about their advance care planning by initiating discussions about end-of-life care' and stated that 'these discussions should prepare patients with advanced COPD for a lifethreatening exacerbation of their chronic disease ...' while '...providing information on probable outcomes and the existence of palliative interventions...' 
Despite more stays in ICU and more resource-intensive care than patients with cancer [9], COPD patients are not always well informed about their disease in general and about the risk of ICU admission in particular. They are also poorly informed about what an ICU stay entails. Semi-structured interviews conducted in 21 patients with advanced COPD revealed that many of them were unaware of the progressive nature of the condition and few were aware that they could die from their disease [10]. Conversations about ICU care with COPD patients and their relatives during or after an acute episode are frequently conducted by intensivists rather than attending pulmonologists, in a context in which ICU stressors and post-traumatic disorders $[11,12]$ can interfere with decisions, preferences and values. In addition, COPD patients are particularly prone to psychiatric disorders, with a high prevalence of anxiety $[13,14]$. As previously implemented in cancer patients, advance care planning could therefore improve the patient's quality of life without inducing higher rates of major depressive disorder [15].

The first objective of this study was to provide a description of the information provided by pulmonologists to their COPD patients at regular follow-up visits and of the information received by COPD patients and their relative about COPD-related ICU stays. Because decision-making processes are bound to influence the information given to patients, we aimed to describe how pulmonologists based their decisions for ICU admission and intubation in comparison with intensivists.

\section{Material and methods}

This study is an ancillary part of a previously published study [12] conducted in 19 French ICUs over an 18-month period after approval by the appropriate Institutional Review Board (Comité de protection des personnes Ile de France 6, La Pitié Salpêtrière, Paris, France). Completing the questionnaire was taken as evidence of consent to study participation. Data presented here concerning patients, relatives and pulmonologists have not been previously reported in a published article.

\section{Patient data}

The previously published study [12] provided a detailed description of data collection and quality control procedures. Briefly, patients with COPD admitted to the 19 participating ICUs were prospectively screened and were included when they spent more than 24 hours in the ICU for COPD exacerbation. Exclusion criteria included ICU death, cognitive dysfunction, language barriers or severe psychiatric disorders. The patient's relatives (one relative per patient) were included when they understood French. Collected variables included demographic characteristics, illness severity on admission, baseline psychological status and evaluation of anxiety or depression at ICU discharge [12]. At ICU discharge, patients and relatives filled in a questionnaire describing the information they had received about COPD before the acute episode and the terms used by their physicians (closed-ended questions).

\section{Physician data}

A postal-based survey was administered to 200 pulmonologists randomly selected from the French language society of respiratory medicine ('Société de Pneumologie de Langue Française') database that comprises about 2,000 names. The survey was based on a case report and was designed to describe the physician's practical approach to a 50-year-old 50 pack-year COPD patient with a forced expiratory volume in 1 second (FEV1) of $30 \%$ predicted. Questions pertained to general information about the disease, use of oxygen, and use of non-invasive and invasive mechanical ventilation. A 15-item questionnaire on COPD severity and outcomes was used in which each item was explored by a four-level Likert-type scale ('never', 'sometimes', 'frequently' and 'always'). The questionnaire was returned by 173 of the 200 physicians surveyed (138 with no missing data).

Factors influencing decisions to refrain from proposing an ICU admission and invasive mechanical ventilation were also investigated by means of a 16 -item questionnaire, in which each item was scored from 0 to 10 (with ' 0 ' corresponding to 'no impact on the decision' and ' 10 ' corresponding to 'major impact on the decision'). This part of the questionnaire was also administered to 175 ICU physicians derived from the 'Famirea' database (135 responses, 119 with no missing data) [11].

\section{Statistical analysis}

Statistical analysis was performed with SAS 9.1 software package (SAS institute Inc, Cary, NC, USA). The results are reported as median and interquartile range or as numbers and percentages. The baseline characteristics of the surveyed physicians - pulmonologists vs. intensivists were compared using a chi-square test for categorical variables and a non-parametric Mann-Whitney test for continuous variables. The answers of the pulmonologists and intensivists to the 16-item questionnaire exploring factors influencing ICU admission and intubation decisions were studied according to principal component analysis [16,17], using Kaiser's criterion to choose the number of components included [18]. Principal component analysis was based on questionnaires with no missing data (138 pulmonologists, 119 intensivists). This approach aims at reducing the complexity of a data set to lower dimensions by transforming the original coordinate system describing the data into a new set of coordinates (called 'principal components') with a common origin and perpendicular directions. The first principal component is 
a vector that points in the direction of highest variance. The second principal component points in the direction of the second highest variance, and so on. Relationships between variables are derived from the analysis of cell frequencies within a two-way contingency table. The relationships between one category of respondents (intensivists or pulmonologists) and their responses to the questionnaires determined a point of which the coordinates depend of the direction and strength of the association. The weights given to these items are higher when they have a positive Y-coordinate. Thus, in our study, each item in each category of responders was labelled as either a 'high weight' (positive Y-coordinate) or a 'low weight' item (negative Y-coordinate). In addition, we provide the Euclidean distance between the factors coordinates of a given component in the 'intensivists' data set and in the 'pulmonologists' data set. The higher the Euclidean distance, the larger the discrepancy between the item's weight in the 'intensivists' data set and in the 'pulmonologists' data set.

Differences were considered significant when the probability $P$ of a type I error was less than $5 \%$.

\section{Results}

Characteristics of patients, relatives and physicians surveyed One hundred and twenty six of the 164 patients with COPD admitted during the study period were included in the study (see flow chart on Figure 1). One hundred and two relatives were also included (Figure 1, Table 1). Figure 1 and Table 2 indicate the characteristics of the
173 pulmonologists and 135 intensivists. Most pulmonologists $(84 \%)$ had gained experience in intensive care during their residency, while $41 \%$ of intensivists reported some training in pulmonology.

\section{Communication between patients and pulmonologists}

Communication between COPD patients and pulmonologist was perceived as satisfactory by patients who attributed a score of $9 / 10$ (IQR, 7 to 10) and by their relatives who attributed a score of $8 / 10$ (5 to 9). Figure 2 compares the terms used by patients, their relatives and pulmonologists to discuss the disease. Patients and their relatives often reported use of the terms 'emphysema' and 'respiratory insufficiency' by their physician, but very rarely the use of 'COPD'. Of note, 'asthma' and 'allergy' were used by more than $50 \%$ of patients and their relatives, although these terms were never used by pulmonologists. About $80 \%$ of physicians, patients and relatives used the expression 'tobacco-related disease'.

For $31 \%$ of patients $(\mathrm{n}=39)$ surveyed, ICU admission had never been expected. Only 56\% reported having discussed this possibility with their general practitioner and/or pulmonologist. Only $54 \%$ of relatives $(n=51)$ surveyed were aware that the patient could possibly require ICU admission.

Figure 3 describes the frequency with which the surveyed pulmonologists reported informing their COPD patients about the 15 items of the severity and outcomes questionnaire. The severity and irreversibility of the disease was mentioned almost systematically. The

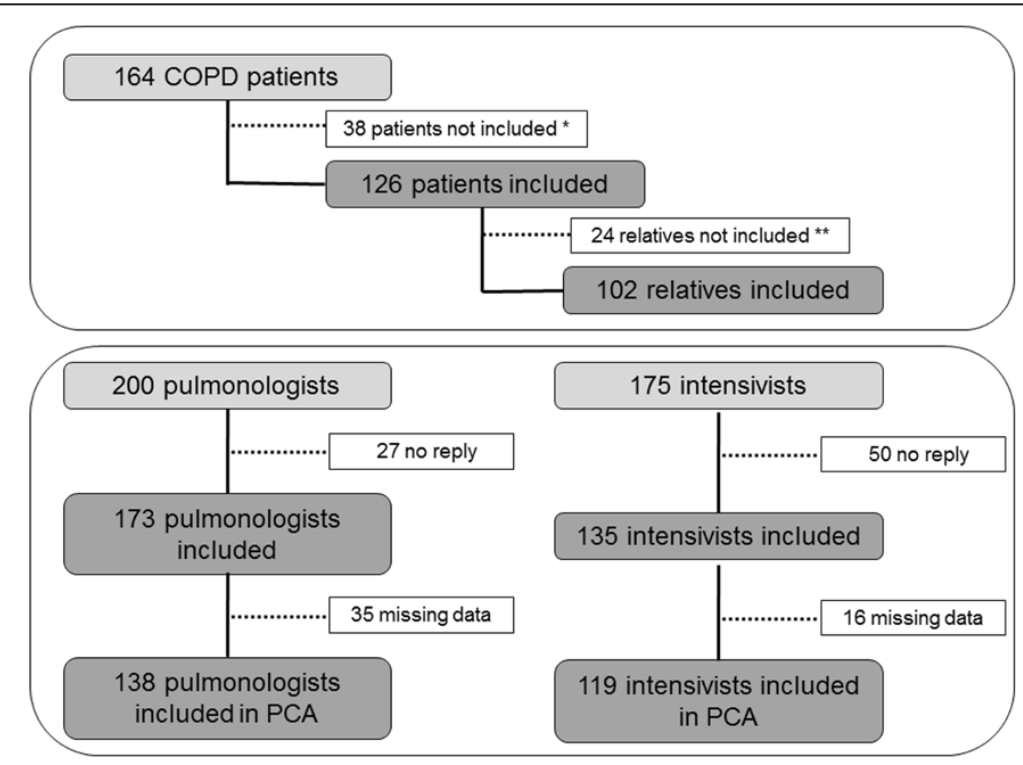

Figure 1 Study flow chart. *Reasons for non-inclusion of patients: death in ICU ( $n=27)$, mental incompetence $(n=7)$, unexpected ICU discharge $(n=3)$ and refusal $(n=1)$; **among the 126 included COPD patients, 14 lived alone and had no relatives; among the 112 relatives potentially available to participate, seven could not speak French, and three refused to participate. COPD, chronic obstructive pulmonary disease; ICU, intensive care unit; PCA, principal component analysis. 
Table 1 Characteristics of patients and relatives

\begin{tabular}{|c|c|}
\hline Patients $(n=126)$ & $\begin{array}{c}\text { Median (25th-75th) } \\
\text { or } n(\%)\end{array}$ \\
\hline Age, years & $67(57-75)$ \\
\hline Male & $79(62)$ \\
\hline WHO performance scale - stage 3 or $4^{£}$ & $71(57)$ \\
\hline Body mass index, kg.m $\mathrm{m}^{-2}$ & $26(22-32)$ \\
\hline SAPS $\|$ & $30(23-40)$ \\
\hline Symptoms of anxiety at baseline & $31(24)$ \\
\hline Symptoms of depression at baseline & $26(20)$ \\
\hline Time since COPD diagnosis, months & $36(9-240)$ \\
\hline \multicolumn{2}{|l|}{ COPD management } \\
\hline Regular general practitioner visits & $110(87)$ \\
\hline Regular pulmonologist visits & $76(60)$ \\
\hline First hospitalization for COPD exacerbation & $35(28)$ \\
\hline First ICU admission & $58(46)$ \\
\hline Had prior knowledge of respiratory disease & $107(84)$ \\
\hline \multicolumn{2}{|l|}{ Relatives $(n=102)$} \\
\hline \multicolumn{2}{|l|}{ Tie with the patient } \\
\hline Spouse & $55(54)$ \\
\hline Children & $10(10)$ \\
\hline Brother/sister & $3(3)$ \\
\hline Father/mother & $5(5)$ \\
\hline Other family tie & $17(17)$ \\
\hline Friends & $12(11)$ \\
\hline Only caregivers at home & $38(37)$ \\
\hline Had prior knowledge of patient's respiratory disease & $87(87)$ \\
\hline Since, months & $60(24-120)$ \\
\hline
\end{tabular}

${ }^{{ } W H O}$ performance scale: World Health Organization performance scale to describe how well patients are. This score ranged from 0 to 5 , is also called performance status [19]. COPD, chronic obstructive pulmonary disease; ICU, intensive care unit; SAPS II, Simplified Acute Physiology Score II.

risk of an exacerbation requiring a hospital stay in a respiratory medicine ward was mentioned 'always' or 'frequently' in more than two-thirds of cases. In contrast, the possibility of an ICU admission was mentioned 'always' or 'frequently' in about one-third of cases, and 'never' in 50\% of cases. The possibility of intubation was never or only sometimes mentioned in $70 \%$ of cases. The patient's preferences concerning ICU admission, intubation and tracheotomy were never or only sometimes mentioned in $>70 \%$ of cases.

\section{Factors contributing to the physicians' attitude toward ICU admission and intubation}

Tables 3 and 4 shows the results of principal component analysis.

\section{ICU admission}

The largest Euclidean distances between the answers of the pneumologists and that of the intensivists were noted for the items related to personal views (that is 'general practitioner's opinion'; 'patient's opinion'; 'family's opinion'; 'respiratory nurse's opinion'; 'another pulmonologist's opinion'). The weights attributed to these items by pulmonologists were higher than those attributed to the same items by intensivists (Table 3). Similar differences were also observed for 'no family'. Pulmonologists' and intensivists' responses were also in opposite direction for items related to medical status (that is 'FEV $1<30 \%$ predicted'; 'home oxygen'; 'number of hospitalizations during the last year'; 'number of hospitalizations with mechanical ventilation during the last year'). Intensivists attributed a higher weight to these items than pulmonologists (Table 3).

\section{Intubation}

The differences between pulmonologists and intensivists regarding intubation were less marked than those concerning ICU admission. The 'opinion-related' items and 'age' were given similar - and high - weights by both categories of physicians (Table 4). Pulmonologists' and intensivists' responses displayed discrepancies concerning 'physician's personal perception of patient's quality of life' and 'smoking cessation', as pulmonologists attributed higher weight to these items than intensivists, while an opposite trend was observed for the 'heart failure' item.

\section{Discussion}

This study highlights some of the barriers to patientphysician dialogue concerning COPD in general, and severe acute episodes of the disease in particular, despite the fact that patients and pulmonologists both rated the quality of their reciprocal communication as being very high. This study also shows that pulmonologists and intensivists have different perceptions of the decision-making process pertaining to these episodes, providing insight to future approaches designed to improve information of COPD patients about their disease.

The vocabulary used by patients, relatives, and pulmonologists to describe the disease illustrates the communication difficulties related to COPD. The three categories of respondents used 'chronic bronchitis', 'emphysema' and 'respiratory insufficiency' with comparable frequencies, which is a positive result. However, COPD patients and their relatives fairly frequently used the terms 'asthma' and 'allergy', which indicates a certain degree of confusion, suggesting that pulmonologists were not their unique source of information. These observations are consistent with previously published studies indicating that COPD patients have a poor knowledge of their disease [20-22]. In particular, COPD patients also have a poor understanding of the term 'exacerbation' [23].

The findings of this study also indicate that the risk of severe COPD exacerbations (those requiring ICU admission and mechanical ventilatory assistance) is a difficult 
Table 2 Characteristics of pulmonologists and intensivists

\begin{tabular}{lccc}
\hline & $\begin{array}{c}\text { Pulmonologists } \\
(\mathbf{n}=\mathbf{1 7 3})\end{array}$ & $\begin{array}{c}\text { Intensivists } \\
(\mathbf{n}=\mathbf{1 3 5})\end{array}$ & $\boldsymbol{P}$ \\
\hline Age (years) & $50(44-56)$ & $35(30-42)$ & $<0.001$ \\
Male (n) & $128(77)$ & $90(67)$ & 0.03 \\
Practice & & & $<0.001$ \\
$\quad$ university hospital & $44(25)$ & $89(66)$ & \\
$\quad$ general hospital & $62(36)$ & $46(34)$ & \\
$\quad$ private practice & $67(39)$ & $0(0)$ & \\
$\begin{array}{l}\text { Past experience } \\
\text { in pulmonology }\end{array}$ & & & \\
$\quad$ None & $0(0)$ & $80(59)$ & \\
$\quad \leq 1$ year & $0(0)$ & $25(18)$ & \\
1- 2 years & $2(1)$ & $13(10)$ & \\
$>2$ years & $167(99)$ & $17(13)$ & \\
$\begin{array}{l}\text { Past experience in } \\
\text { intensive care }\end{array}$ & & & $<0.001$ \\
$\quad$ None & $28(16)$ & $0(0)$ & \\
$\leq 1$ year & $76(44)$ & $24(18)$ & \\
$\leq 2$ years & $17(10)$ & $13(10)$ & \\
$>2$ years & $52(30)$ & $98(72)$ & \\
\hline
\end{tabular}

subject to discuss with patients and relatives. Fifty percent of the surveyed pulmonologists reported that they never or only 'sometimes' informed their patients corresponding to this clinical setting that they were at risk of ICU admission in the event of a severe exacerbation. These rates increased to $60 \%$ concerning non-invasive ventilation, $70 \%$ concerning intubation, and $90 \%$ concerning tracheotomy. Of note, the surveyed pulmonologists were not asked to go beyond the case report and describe how disease severity influenced the information they gave to their patients. In line with the above findings, $31 \%$ of patients $(\mathrm{n}=39)$ and $54 \%$ of relatives $(n=51)$ reported that they had not previously expected ICU admission. Bearing in mind that $54 \%$ $(n=68)$ of patients in this study had been previously admitted to an ICU and were therefore unlikely to be unaware of this possibility, this figure of $31 \%$ appears to be extremely high. In contrast, it is likely that almost all COPD patients in the study with no previous ICU stay were unprepared for this possibility.

As critically ill patients are usually unable to make decisions and as nearly one half of surrogates do not understand the concept of surrogate decision-making $[24,25]$, it would be particularly useful to discuss the COPD patient's preferences and advanced care planning. However, only a small proportion of the surveyed pulmonologists reported discussing the patient's preferences in relation to ICU admission, intubation, and tracheotomy (Figure 3), which is consistent with recent literature on this issue [10,26-29]. Nevertheless, many COPD patients express the desire to discuss these issues [29] and pulmonologists in the present study attributed high weights to items related to 'the patient's or family's personal views' during decision-making processes concerning ICU admission and intubation. There are a number of barriers to advanced ICU care planning for COPD patients. The main barriers acknowledged by pulmonologists during end-of-life discussions were: 'too little time during the appointment', 'a desire to preserve the patient's hope', 'a feeling that the patient was not ready to talk about the care she/he wants' [27]. Few studies have been devoted to communication barriers identified by pulmonologists concerning the risk of ICU admission and the resulting prognosis, despite the recent recommendations in the Global Initiative for Chronic Obstructive Lung Disease (GOLD) report [30]. Some of these barriers may be lack of time, lack of intensive care experience, difficulties talking about another speciality or discomfort with giving bad news. Moreover, terms are confusing (Figure 2) and patients may often be reluctant to ask questions. Thus pulmonologists may feel they have communicated information while the patient may feel they received little. Several simple measures, mostly based on improving communication strategies, could be implemented. For instance, including non-pulmonologists in discussions [31], informative handouts to educate families about critical illness and intensive therapies [32], as well as proactive and effective communication strategies [24,33] could possibly overcome these pitfalls. Preparing COPD patients for the risk of severe exacerbations, as well as defining their preferences in relation to ICU admission, intubation and tracheotomy could have a beneficial impact on their perceived overall quality and satisfaction with care [34-36] and could also decrease the high psychological burden of ICU on COPD patients and their relatives $[12,15]$.

Prognostic factors of COPD have been clearly identified $[3,5,6,37]$. Informing COPD patients about ICU admission and the subsequent methods of care necessarily implies taking these prognostic factors into account. However, the results of this study indicate that the pulmonologists surveyed, compared to intensivists, attributed more weight to items related to 'personal views' (of the patient, family, other healthcare practitioners) and less weight to more objective elements, including well-documented prognostic factors (such as low FEV1, home oxygen, and so on). Between-specialist heterogeneities in the care of COPD patients are well known [38-40] and could help to explain the results of this study. It can be postulated that it is more difficult to choose when and how to address end-oflife related issues such as ICU admission with patients when decision-making criteria are subjective rather than based on objective criteria. It is noteworthy that the nature of the information given to patients depends on the clinician's evaluation of the prognosis: in the field of $\mathrm{COPD}$, there is evidence that an unwarranted prognostic 


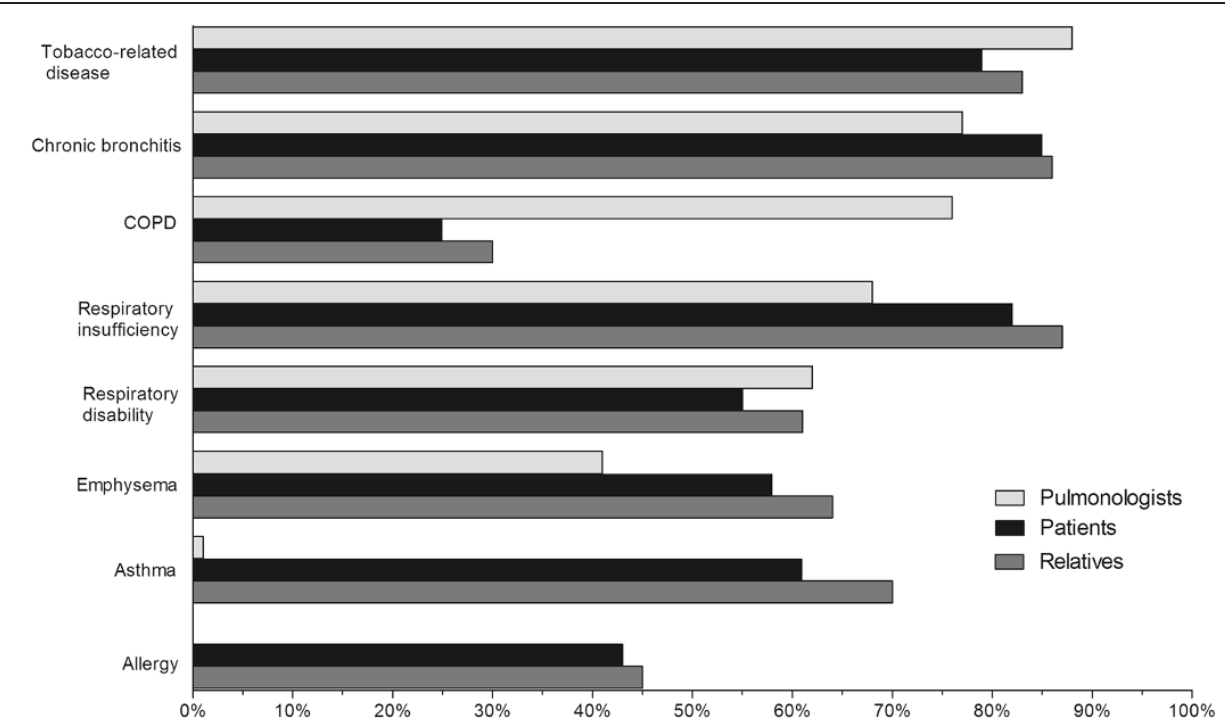

Figure 2 Terminology used by patients, relatives and pulmonologists to discuss the disease. The results are expressed as percentages of responses. COPD, chronic obstructive pulmonary disease.

pessimism can be a source of under-treatment [41]. Pulmonologist-intensivist differences were less marked in relation to the intubation decision-making process than in relation to the ICU admission decision-making process. These results highlight the need for closer collaboration between pulmonologists and intensivists. Multidisciplinary meetings, systematic experience of intensive care during pulmonology residencies and post-ICU consultation by intensivists, should be discussed.

This study presents several limitations. The pulmonologists surveyed were not the healthcare providers of the patients interviewed. An in-depth evaluation of COPD knowledge was not conducted, but the assessment was restricted to the terms used to explain COPD in a specific population with severe COPD following an ICU stay. In addition, our study focused on ICU survivors. Thus, we do not know about the information given to the non-survivors of critical illness. Since they were more severely ill, we cannot rule out they might have received more information in advance. The way in which pulmonologists and intensivists stratify their decision-making process according to disease severity and the decision-making process concerning major

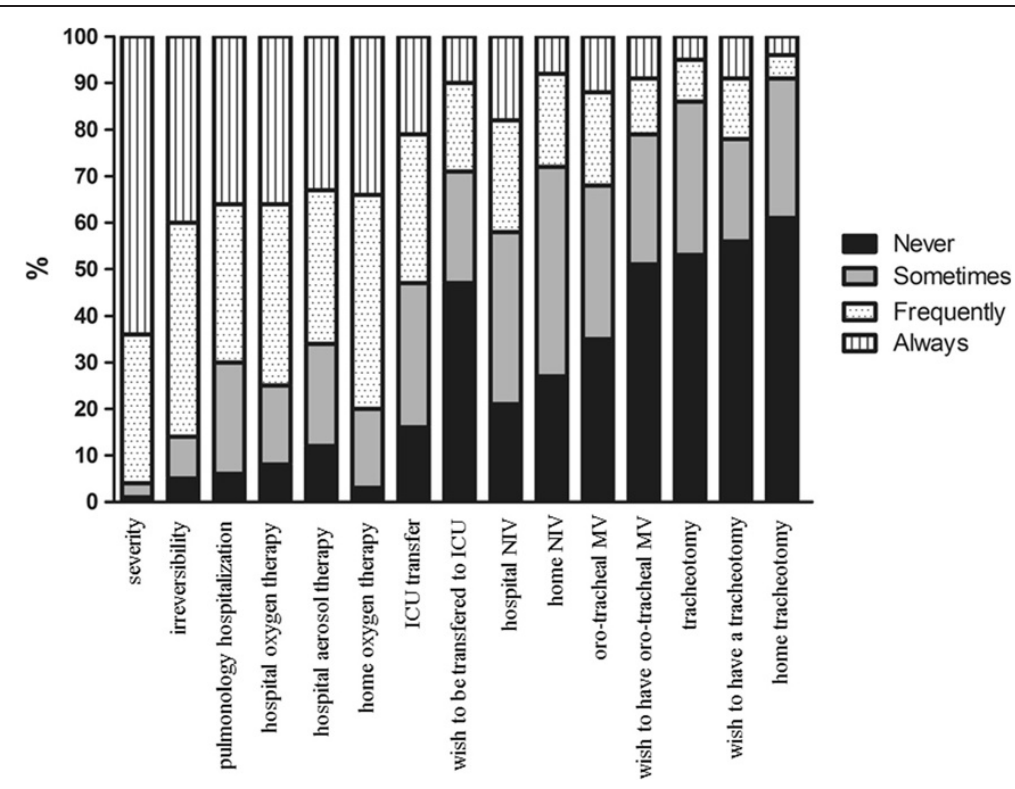

Figure 3 COPD-related issues discussed by the surveyed pulmonologists with their patients. COPD, chronic obstructive pulmonary disease; ICU, intensive care unit; MV, mechanical ventilation; NIV, non-invasive ventilation. 
Table 3 Factors negatively influencing decisions of non-admission to the ICU among pulmonologists and intensivists (16-item questionnaire)

\begin{tabular}{|c|c|c|c|}
\hline & $\begin{array}{l}\text { High weight for } \\
\text { pulmonologists }\end{array}$ & $\begin{array}{l}\text { High weight for } \\
\text { intensivists }\end{array}$ & $\begin{array}{c}\text { Euclidean } \\
\text { distance }\end{array}$ \\
\hline Respiratory nurse's opinion & + & - & 2.804 \\
\hline Other pulmonologist/intensivist's opinion & + & - & 2.686 \\
\hline General practitioner's opinion & + & - & 2.505 \\
\hline Home non-invasive ventilation & - & + & 2.447 \\
\hline Family's opinion & + & - & 2.444 \\
\hline Home oxygen & - & + & 2.256 \\
\hline Patient's opinion & + & - & 2.187 \\
\hline No family & + & - & 1.924 \\
\hline Forced expiratory volume in 1 second $<30 \%$ predicted & - & + & 1.757 \\
\hline Number of hospitalizations in last year & - & + & 1.381 \\
\hline Number of hospitalizations with mechanical Ventilation in last year & - & + & 1.293 \\
\hline Depression & + & + & 0.908 \\
\hline Smoking cessation & + & + & 0.792 \\
\hline Heart failure & + & + & 0.570 \\
\hline Age & - & - & 0.385 \\
\hline Physician's perception of the patient's quality of life & - & - & 0.330 \\
\hline
\end{tabular}

These data were obtained by principal component analysis. Large Euclidean distances indicate substantial differences between pulmonologists' and intensivists' responses, while short distances indicate similarity. The mark ' + ' indicates a positive Y-coordinate in the principal component analysis which means an important weight given to this item by the 'pulmonologists' data set or the 'intensivists' data set. Conversely, the mark '-' displays a negative Y-coordinate which indicates a low item's weight.

Table 4 Factors negatively influencing decisions of non-intubation among pulmonologists and intensivists (16-item questionnaire)

\begin{tabular}{|c|c|c|c|}
\hline & $\begin{array}{l}\text { High weight for } \\
\text { pulmonologists }\end{array}$ & $\begin{array}{l}\text { High weight for } \\
\text { intensivists }\end{array}$ & $\begin{array}{c}\text { Euclidean } \\
\text { distance }\end{array}$ \\
\hline General practitioner's opinion & - & + & 1.898 \\
\hline Smoking cessation & + & - & 1.639 \\
\hline Physician's perception of the patient's quality of life & + & - & 1.587 \\
\hline No family & - & + & 1.547 \\
\hline Respiratory nurse's opinion & + & + & 1.237 \\
\hline Heart failure & - & + & 1.222 \\
\hline Depression & + & + & 0.916 \\
\hline Number of hospitalizations in last year & - & - & 0.833 \\
\hline Age & + & + & 0.735 \\
\hline Home oxygen & - & - & 0.702 \\
\hline Family's opinion & + & + & 0.594 \\
\hline Forced expiratory volume in 1 second $<30 \%$ & - & - & 0.566 \\
\hline Predicted number of hospitalizations with mechanical ventilation in last year & - & - & 0.496 \\
\hline Other pulmonologist/intensivist's opinion & + & + & 0.477 \\
\hline Home non-invasive ventilation & - & - & 0.475 \\
\hline Patient's opinion & + & + & 0.331 \\
\hline
\end{tabular}


ICU issues in COPD, such as non-invasive ventilation and tracheostomy that may also have been relevant were also not investigated.

\section{Conclusions}

Nevertheless, our observations confirm that further effort is required to enable COPD patients to play a fully informed role in end-of-life decisions and more specifically in decisions concerning ICU admission and intubation, while keeping encouragement and support to maintain life as productive as possible. The nature and timing of this communication should probably be more clearly defined, and should take into account the known objective prognostic factors. Given the discrepancies in the decision-making process between pulmonologists and intensivists, a more collaborative approach should probably be discussed. Further interventional studies are now warranted.

\section{Key messages}

- Patients with COPD have a poor knowledge of their disease.

- Only a small proportion of pulmonologists report discussing the patient's preferences in relation to ICU admission, intubation, and tracheotomy.

- Pulmonologists and ICU physicians have different perceptions of the decision-making process pertaining to ICU admission and intubation.

- Further efforts are required to enable COPD patients to play a fully informed role in end-of-life decisions and more specifically in decisions concerning ICU admission and intubation.

\section{Abbreviations \\ COPD: chronic obstructive pulmonary disease; FEV1: forced expiratory volume in 1 second; ICU: intensive care unit.}

\section{Competing interests}

The authors declare that they have no competing interests.

\section{Authors' contributions}

MS is the guarantor of the manuscript and takes responsibility for the integrity of the work as a whole, from inception to published article. MC contributed to data collection, data analysis, and the revision of the manuscript. SDM contributed to data collection and the revision of the manuscript. NB contributed to data collection and the revision of the manuscript. NR contributed to data collection and the revision of the manuscript. EA contributed to data collection, data analysis and the revision of the manuscript. MS contributed to data analysis, statistical analysis, and the writing and revision of the manuscript. AD contributed to data analysis, statistical analysis and the revision of the manuscript. EBD contributed to data analysis, statistical analysis, and the writing and revision of the manuscript. TS contributed to data analysis, and the writing and revision of the manuscript. All authors read and approved the final manuscript.

\section{Authors' information}

MS is an ICU physician. AD is a professor of intensive care.EBD is a statistician. MC is an ICU fellow. SDM is a pulmonologist. NB is an ICU physician. NR is a professor of pulmonology. EA is a professor of intensive care. TS is a professor of pulmonology. He is the chair of the pulmonology department and medical ICU in the Pitie Salpetriere hospital in Paris.

\section{Acknowledgements}

Matthieu Schmidt was supported by the Société de Réanimation de Langue Française, the 'Fonds de dotation Recherche en Santé Respiratoire, 2012' and the 'Fonds d'Etudes et de Recherche du Corps Medical (FERCM) des Hôpitaux de Paris'. Alexandre Demoule was supported by CARDIF (Centre d'Assistance Respiratoire à Domicile d'lle-de-France), and the Société de Pneumologie de Langue Française, Paris, France. The study was supported by a grant from the Assistance-Publique Hôpitaux de Paris (AOM 04139) and the Société de Réanimation de Langue Française.

\section{Author details}

'Sorbonne Universités, UPMC Univ Paris 06, UMR_S 1158 'Neurophysiologie Respiratoire Expérimentale et Clinique', 47-83 boulevard de l'Hôpital, 75013 Paris, France. ${ }^{2}$ INSERM, UMR_S 1158 'Neurophysiologie Respiratoire Expérimentale et Clinique', 47-83 boulevard de l'Hôpital, 75013 Paris, France. ${ }^{3}$ AP-HP, Groupe Hospitalier Pitié-Salpêtrière Charles Foix, Service de Pneumologie et Réanimation Médicale (Département 'R3S'), 47 boulevard de I'Hôpital, F-75013 Paris, France. ${ }^{4}$ Sorbonne Universités, UPMC Univ Paris 06, UMR_S 974, 47-83 boulevard de l'Hôpital, 75013 Paris, France. ${ }^{5}$ INSERM, UMR_S 974, F-75005 Paris, France. ${ }^{6}$ Hôpitaux de Paris, Hôpital Saint Louis, Service de Biostatistique, 1 avenue Claude Vellefaux, 75010 Paris, France. ${ }^{7}$ Hôpitaux de Paris, Hôpital Saint Louis, Service de Réanimation Médicale, 1 avenue Claude Vellefaux, 75010 Paris, France. ${ }^{8}$ Hôpitaux de Paris, Hôpital Cochin - Site Val de Grâce, Service de Pneumologie et Soins Intensifs Respiratoires, Université Paris Descartes, 27 Rue du Faubourg Saint-Jacques, F-75014 Paris, France.

Received: 31 July 2013 Accepted: 20 May 2014

Published: 4 June 2014

\section{References}

1. Jemal A, Ward E, Hao Y, Thun M: Trends in the leading causes of death in the United States, 1970-2002. JAMA 2005, 294:1255-1259.

2. Funk GC, Bauer P, Burghuber OC, Fazekas A, Hartl S, Hochrieser H, Schmutz $R$, Metnitz P: Prevalence and prognosis of COPD in critically ill patients between 1998 and 2008. Eur Respir J 2013, 41:792-799.

3. Gunen H, Hacievliyagil SS, Kosar F, Mutlu LC, Gulbas G, Pehlivan E, Sahin I, Kizkin O: Factors affecting survival of hospitalised patients with COPD. Eur Respir J 2005, 26:234-241.

4. Esteban A, Anzueto A, Frutos F, Alia I, Brochard L, Stewart TE, Benito S, Epstein SK, Apezteguia C, Nightingale P, Arroliga AC, Tobin MJ, Mechanical Ventilation International Study Group: Characteristics and outcomes in adult patients receiving mechanical ventilation: a 28-day international study. JAMA 2002, 287:345-355.

5. Connors AF Jr, Dawson NV, Thomas C, Harrell FE Jr, Desbiens N, Fulkerson WJ, Kussin P, Bellamy P, Goldman L, Knaus WA: Outcomes following acute exacerbation of severe chronic obstructive lung disease. The SUPPORT investigators (Study to Understand Prognoses and Preferences for Outcomes and Risks of Treatments). Am J Respir Crit Care Med 1996, 154:959-967.

6. Seneff MG, Wagner DP, Wagner RP, Zimmerman JE, Knaus WA: Hospital and 1-year survival of patients admitted to intensive care units with acute exacerbation of chronic obstructive pulmonary disease. JAMA 1995, 274:1852-1857.

7. Ram FS, Picot J, Lightowler J, Wedzicha JA: Non-invasive positive pressure ventilation for treatment of respiratory failure due to exacerbations of chronic obstructive pulmonary disease. Cochrane Database Syst Rev 2004, 3:CD004104

8. Standards for the diagnosis and management of patients with COPD. Version 1.2. [http://www.thoracic.org/go/copd]

9. Au DH, Udris EM, Fihn SD, McDonell MB, Curtis JR: Differences in health care utilization at the end of life among patients with chronic obstructive pulmonary disease and patients with lung cancer. Arch Intern Med 2006, 166:326-331.

10. Gardiner C, Gott M, Small N, Payne S, Seamark D, Barnes S, Halpin D, Ruse C: Living with advanced chronic obstructive pulmonary disease: patients concerns regarding death and dying. Palliat Med 2009, 23:691-697.

11. Azoulay E, Pochard F, Kentish-Barnes N, Chevret S, Aboab J, Adrie C, Annane D, Bleichner G, Bollaert PE, Darmon M, Fassier T, Galliot R, Garrouste-Orgeas M, Goulenok C, Goldgran-Toledano D, Hayon J, Jourdain M, Kaidomar M, Laplace C, Larché J, Liotier J, Papazian L, Poisson C, Reignier J, Saidi F, Schlemmer B, 
FAMIREA Study Group: Risk of post-traumatic stress symptoms in family members of intensive care unit patients. Am J Respir Crit Care Med 2005, 171:987-994.

12. de Miranda S, Pochard F, Chaize M, Megarbane B, Cuvelier A, Bele N, Gonzalez-Bermejo J, Aboab J, Lautrette A, Lemiale V, Roche N, Thirion M, Chevret S, Schlemmer B, Similowski T, Azoulay E: Postintensive care unit psychological burden in patients with chronic obstructive pulmonary disease and informal caregivers: a multicenter study. Crit Care Med 2011 39:112-118.

13. Maurer J, Rebbapragada V, Borson S, Goldstein R, Kunik ME, Yohannes AM, Hanania NA: Anxiety and depression in COPD: current understanding, unanswered questions, and research needs. Chest 2008, 134:43S-56S.

14. Ng TP, Niti M, Tan WC, Cao Z, Ong KC, Eng P: Depressive symptoms and chronic obstructive pulmonary disease: effect on mortality, hospital readmission, symptom burden, functional status, and quality of life. Arch Intern Med 2007, 167:60-67.

15. Wright AA, Zhang B, Ray A, Mack JW, Trice E, Balboni T, Mitchell SL, Jackson VA, Block SD, Maciejewski PK, Prigerson HG: Associations between end-of-life discussions, patient mental health, medical care near death, and caregiver bereavement adjustment. JAMA 2008, 300:1665-1673.

16. Pearson $\mathrm{K}$ : On lines and planes of closest fit to systems of points in space. Philos Mag Series 6 1901, 2:559-572.

17. Wold S, Esbensen K, Geladi P: Principal component analysis. Chemom Intell Lab Syst 1987, 2:37-52.

18. Kaiser HF: Directional statistical decisions. Psychol Rev 1960, 67:160-167.

19. Oken MM, Creech RH, Tormey DC, Horton J, Davis TE, McFadden ET, Carbone PP: Toxicity and response criteria of the Eastern Cooperative Oncology Group. Am J Clin Oncol 1982, 5:649-655.

20. Barr RG, Celli BR, Mannino DM, Petty T, Rennard SI, Sciurba FC, Stoller JK, Thomashow BM, Turino GM: Comorbidities, patient knowledge, and disease management in a national sample of patients with COPD. Am J Med 2009, 122:348-355.

21. Emtner M, Hedin A, Andersson M, Janson C: Impact of patient characteristics, education and knowledge on emergency room visits in patients with asthma and COPD: a descriptive and correlative study. BMC Pulm Med 2009, 9:43.

22. Hernandez P, Balter M, Bourbeau J, Hodder R: Living with chronic obstructive pulmonary disease: a survey of patients' knowledge and attitudes. Respir Med 2009, 103:1004-1012.

23. Kessler R, Stahl E, Vogelmeier C, Haughney J, Trudeau E, Lofdahl CG, Partridge MR: Patient understanding, detection, and experience of COPD exacerbations: an observational, interview-based study. Chest 2006, 130:133-142.

24. Dales RE, O'Connor A, Hebert P, Sullivan K, McKim D, Llewellyn-Thomas H: Intubation and mechanical ventilation for COPD: development of an instrument to elicit patient preferences. Chest 1999, 116:792-800.

25. LeClaire MM, Oakes JM, Weinert CR: Communication of prognostic information for critically ill patients. Chest 2005, 128:1728-1735.

26. Curtis JR, Engelberg RA, Nielsen EL, Au DH, Patrick DL: Patient-physician communication about end-of-life care for patients with severe COPD. Eur Respir J 2004, 24:200-205.

27. Knauft E, Nielsen EL, Engelberg RA, Patrick DL, Curtis JR: Barriers and facilitators to end-of-life care communication for patients with COPD. Chest 2005, 127:2188-2196.

28. Janssen DJ, Curtis JR, Au DH, Spruit MA, Downey L, Schols JM, Wouters EF, Engelberg RA: Patient-clinician communication about end-of-life care for Dutch and US patients with COPD. Eur Respir J 2011, 38:268-276.

29. Momen N, Hadfield P, Kuhn I, Smith E, Barclay S: Discussing an uncertain future: end-of-life care conversations in chronic obstructive pulmonary disease. A systematic literature review and narrative synthesis. Thorax 2012, 67:777-780.

30. Global strategy for the diagnosis, management, and prevention of chronic obstructive pulmonary disease. [http://www.goldcopd.org/ guidelines-global-strategy-for-diagnosis-management.html]

31. Rabow MW, Petersen J, Schanche K, Dibble SL, McPhee SJ: The comprehensive care team: a description of a controlled trial of care at the beginning of the end of life. J Palliat Med 2003, 6:489-499.

32. Lautrette A, Darmon M, Megarbane B, Joly LM, Chevret S, Adrie C, Barnoud D, Bleichner G, Bruel C, Choukroun G, Curtis JR, Fieux F, Galliot R, Garrouste-Orgeas M, Georges H, Goldgran-Toledano D, Jourdain M, Loubert G, Reignier J, Saidi F, Souweine B, Vincent F, Barnes NK, Pochard F, Schlemmer B, Azoulay E:
A communication strategy and brochure for relatives of patients dying in the ICU. N Engl J Med 2007, 356:469-478.

33. Au DH, Udris EM, Engelberg RA, Diehr PH, Bryson CL, Reinke LF, Curtis JR A randomized trial to improve communication about end-of-life care among patients with COPD. Chest 2012, 141:726-735.

34. Slatore CG, Cecere LM, Reinke LF, Ganzini L, Udris EM, Moss BR, Bryson CL, Curtis JR, Au DH: Patient-clinician communication: associations with important health outcomes among veterans with COPD. Chest 2010, 138:628-634.

35. Leung JM, Udris EM, Uman J, Au DH: The effect of end-of-life discussions on perceived quality of care and health status among patients with COPD. Chest 2012, 142:128-133.

36. Heffner JE, Fahy B, Hilling L, Barbieri C: Outcomes of advance directive education of pulmonary rehabilitation patients. Am J Respir Crit Care Med 1997, 155:1055-1059.

37. Chu CM, Chan VL, Lin AW, Wong IW, Leung WS, Lai CK: Readmission rates and life threatening events in COPD survivors treated with non-invasive ventilation for acute hypercapnic respiratory failure. Thorax 2004, 59:1020-1025.

38. Bourbeau J, Sebaldt RJ, Day A, Bouchard J, Kaplan A, Hernandez P, Rouleau M, Petrie A, Foster G, Thabane L, Haddon J, Scalera A: Practice patterns in the management of chronic obstructive pulmonary disease in primary practice: the CAGE study. Can Respir J 2008, 15:13-19.

39. Garcia-Aymerich J, Escarrabill J, Marrades RM, Monso E, Barreiro E, Anto JM: Differences in COPD care among doctors who control the disease: general practitioner vs pneumologist. Respir Med 2006, 100:332-339.

40. Paladini L, Hodder R, Bellia V, Marchionni N, Di Bari M, Cecchini I, Pistelli R, Antonelli-Incalzi R: Physician specialty as a source of heterogeneity in the care of patients with COPD. Chest 2011, 140:1666-1667.

41. Wildman MJ, Sanderson C, Groves J, Reeves BC, Ayres J, Harrison D, Young $D$, Rowan K: Implications of prognostic pessimism in patients with chronic obstructive pulmonary disease (COPD) or asthma admitted to intensive care in the UK within the COPD and asthma outcome study (CAOS): multicentre observational cohort study. BMJ 2007, 335:1132.

doi:10.1186/cc13906

Cite this article as: Schmidt et al:: Intensive care unit admission in chronic obstructive pulmonary disease: patient information and the physician's decision-making process. Critical Care 2014 18:R115.

\section{Submit your next manuscript to BioMed Central and take full advantage of:}

- Convenient online submission

- Thorough peer review

- No space constraints or color figure charges

- Immediate publication on acceptance

- Inclusion in PubMed, CAS, Scopus and Google Scholar

- Research which is freely available for redistribution 